See Article page 585.

\section{Commentary: Right ventricular dysfunction after cardiac surgery: Machine learning to teach us what we already know?}

\author{
Edgar Aranda-Michel, BS, ${ }^{\mathrm{a}}$ and \\ Ibrahim Sultan, MD ${ }^{\mathrm{a}, \mathrm{b}}$
}

Most pharmacologic and technologic advances over the past decades to address heart failure have focused on the left ventricle, while allowing the right ventricle (RV) to be a passive bystander. However, most surgeons who perform complex cardiovascular surgery with prolonged ischemic times have been humbled time and again by RV dysfunction postcardiotomy. Despite improvements in myocardial protection, RV failure, when it occurs, carries significant morbidity ${ }^{1,2}$ and is a feared complication after cardiac surgery. ${ }^{3}$ To further investigate this, Lang and colleagues ${ }^{4}$ published their findings in the Journal to characterize patient and surgical variables associated with RV dysfunction. The authors used machine learning techniques to elucidate associations between preoperative factors and echocardiographic assessments of RV function. The main findings of this work were as follows: (1) The largest predictive variables across the trained models were ischemic time and baseline RV function; and (2) RV function decreased intraoperatively in all patients.

The authors are to be commended for their detailed work. It has been well established that ischemic-reperfusion injury after cardiopulmonary bypass can have deleterious effects on ventricular functioning, a phenomenon

From the a Department of Cardiothoracic Surgery, University of Pittsburgh, Pittsburgh, $\mathrm{Pa}$; and ${ }^{\mathrm{b}} \mathrm{Heart}$ and Vascular Institute, University of Pittsburgh Medical Center, Pittsburgh, Pa.

Disclosures: I.S. receives research support from Medtronic and AtriCure. These conflicts are unrelated to this work. E.A.-M. reported no conflicts of interest.

The Journal policy requires editors and reviewers to disclose conflicts of interest and to decline handling or reviewing manuscripts for which they may have a conflict of interest. The editors and reviewers of this article have no conflicts of interest.

Received for publication Nov 21, 2020; revisions received Nov 21, 2020; accepted for publication Nov 23, 2020; available ahead of print Dec 3, 2020.

Address for reprints: Ibrahim Sultan, MD, Division of Cardiac Surgery, Department of Cardiothoracic Surgery, University of Pittsburgh, UPMC Center for Thoracic Aortic Disease, Heart and Vascular Institute, University of Pittsburgh Medical Center, 5200 Centre Ave, Suite 715, Pittsburgh, PA 15232 (E-mail: sultani@upmc.edu).

J Thorac Cardiovasc Surg 2022;164:598-9

$0022-5223 / \$ 36.00$

Copyright (c) 2020 by The American Association for Thoracic Surgery

https://doi.org/10.1016/j.jtcvs.2020.11.126
Check for updates

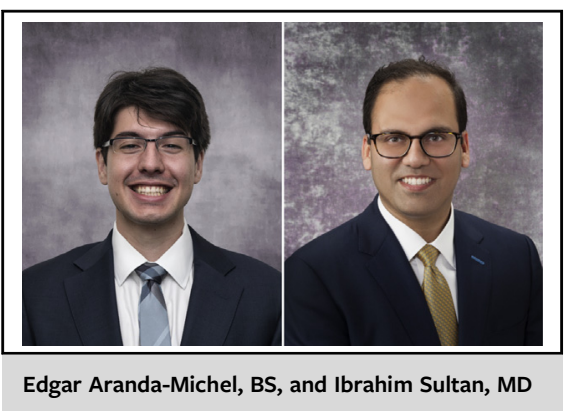

CENTRAL MESSAGE

Preoperative reduced RV func-

tion and long ischemic times are

predictive of postcardiotomy RV

dysfunction.

potentiated by the length of ischemic time. ${ }^{5}$ Although this article reaffirms this fact, there are key points to be made. First, by using machine learning, variable associations are not assumed to be linear. This allows for a more robust evaluation of the preoperative predictive variables on predicting the outcome of RV function. Second, the process of machine learning uses training and validation data sets. Both these sets are randomly chosen, and this process is repeated numerous times, the result being a model that is not overtrained to the patient population. It is important to draw interest to the nonlinear aspect of this process. The authors used variable importance to order the preoperative variables based on the model's predictive power. Of note, ischemic time was the most important variable in the tricuspid annular plane systolic excursion and fractional area change models, but only fourth most important in the strain model. However, when looking at plots of these measures of RV functioning versus ischemic time, there is a stronger nonlinear relationship between them and ischemic time, whereas strain has a more linear relationship. This suggests that measurement of longitudinal strain has a different relationship to the preoperative variables and that more traditional regression techniques are warranted. Nevertheless, across all models, the importance of ischemic time is consistent with prior bodies of work.

Irrespective of the type of RV measurement used, there was a decrease in RV function after cardiopulmonary bypass, although in a small sample size of patients. However, although the ischemic insult resulted in some RV dysfunction, traditionally not many patients develop severe RV dysfunction postcardiotomy. ${ }^{3}$ There are some preliminary data to suggest that perhaps an underlying 
variable associated with the $\mathrm{RV}$ enhances the deleterious effects of ischemia and may cause severe dysfunction. One such proposed mechanism is a sarcoplasmic reticulum calcium ATPase (SERCA2), the downregulation of which has been correlated with decreased RV functioning after an ischemic insult. ${ }^{6}$ Whatever the answer may be, it is imperative to correlate the decrease in RV function to relevant clinical outcomes to appropriately risk stratify patients who may perhaps benefit from enhanced myocardial cardioprotection with additional adjuncts such as systemic or topical hypothermia. However, the authors have done substantial work to associate preoperative variables to intraoperative RV functioning and will undoubtedly continue to progress risk stratification for RV dysfunction.

\section{References}

1. Konstam MA, Kiernan MS, Bernstein D, Bozkurt B, Jacob M, Kapur NK, et al. Evaluation and management of right-sided heart failure: a scientific statement from the American Heart Association. Circulation. 2018;137:e578-622.

2. Sultan I, Kilic A, Kilic A. Short-term circulatory and right ventricle support in cardiogenic shock: extracorporeal membrane oxygenation, Tandem Heart, CentriMag, and Impella. Heart Fail Clin. 2018;14:579-83.

3. Estrada VH, Franco DL, Moreno AA, Gambasica JA, Nunez CC. Postoperative right ventricular failure in cardiac surgery. Cardiol Res. 2016;7:185-95.

4. Lang AL, Huang X, Alfirevic A, Blackstone E, Pettersson G, Singh A, et al. Patient characteristics and surgical variables associated with intraoperative reduced right ventricular function. J Thorac Cardiovasc Surg. 2022;164:585-95.e5.

5. Weman SM, Karhunen PJ, Penttilä A, Järvinen AA, Salminen U-S. Reperfusion injury associated with one-fourth of deaths after coronary artery bypass grafting. Ann Thorac Surg. 2000;70:807-12.

6. Cardounel AJ, Aranda-Michel E, Humar R, Navid W, Kilic A, Lee J, et al. Abstract 12920: identification of SERCA2 as a novel effector and therapeutic target in acute post-operative right ventricular dysfunction. Circulation. 2019;140:A12920. 